\title{
Pendeteksian Kadar Glukosa dalam Darah pada Gejala Diabetes Tipe 1 menggunakan Algoritma K-Nearest Neighbor dengan Metode Nafas
}

\author{
Muhammad Shibgah Aulia ${ }^{a, *}$, Maman Abdurrahman ${ }^{\text {b }}$, Aji Gautama Putrada ${ }^{c}$ \\ ${ }^{a}$ Telkom University, Jln Terusan Buahbatu , Bandung,Indonesia \\ b,c Telkom University, Jlm Terusan Buahbatu, Bandung, Indonesia \\ *correspondence email : shibgahaulia@telkomuniversity.ac.id
}

\begin{abstract}
The goal of this study was to detect glucose levels in the blood using a non-invasive method through human mouth breath. In patients with type 1 mellitus generally have low salivary levels which can cause bad breath or called Halitosis. The method used in this study is using breath sensor in the form of MQ-4 and Figaro TGS-2602 on human mouth breath to get results in the form of hydrogen sulfide (H2S) and methane (CH4) from a person's breath. The results will be obtained in $\mathrm{mg} / \mathrm{dl}$ after the data is obtained by a sensor with a filter the last lowpass was processed using a machine-learning algorithm in the form of $\mathrm{K}$ Nearest Neighbor with the Regression classification method. The results of the 5 diabetes mellitus sample test data and 40 diabetes mellitus training data can detect glucose in the blood with an accuracy of $80 \%$ and will be compared with previous research. Sample 40 training data was taken from several patients who had p diabetes mellitus and non-diabetes mellitus disease using glucometer with 95\% accuracy rate. This system is expected to provide a solution for people with type 1 diabetes mellitus for someone who suffers from the disease..
\end{abstract}

\section{Index Terms - K-Nearest Neighbo; MQ-4; Figaro-TGS2602; Cosine; Lowpass}

\begin{abstract}
Abstrak - Tujuan akhir dari penelitian ini adalah untuk mendeteksi kadar glukosa dalam darah menggunakan metode non-invasive melalui nafas mulut manusia.Pada penderita dibetes melitus tipe 1 umumnya mempunyai kadar saliva yang rendah yang dapat menyebabkan bau mulut atau disebut Halitosis. Metode yang dapat digunakan pada penelitian ini yaitu menggunakan sensor nafas berupa MQ-4 dan Figaro TGS-2602 pada hembusan nafas mulut manusia guna mendapatkan hasil berupa kadar hydrogen sulfide(H2S) dan methane $(\mathrm{CH} 4)$ dari nafas seseorang.Hasil akan didapatkan dalam satuan $\mathrm{mg} / \mathrm{dl}$ setelah data diperoleh oleh sensor dengan filter Lowpass lalu diproses menggunakan algoritma machine-learning berupa K-Nearest Neighbor dengan metode klasifikasi Regression .Hasil dari 5 data tes sampel diabetes melitus serta 40 data training diabetes melitus dapat mendeteksi glukosa dalam darah dengan tingkat akurasi $80 \%$ serta akan dibandingkan dengan riset sebelumnya.Sample 40 data training diambil dari beberapa pasien yang mempunyai pengidap penyakit diabetes melitus dan non-diabetes melitus menggunakan alat glukometer dengan tingkat akurasi alat $95 \%$.Diharapkan sistem ini dapat memberi solusi pada pengidap penyakit diabetes melitus tipe 1 untuk sesorang yang menderita penyakit tersebut.
\end{abstract}

Kata Kunci-K-Nearest Neighbor; MQ-4; Figaro-TGS2602; Regression; Lowpass

\section{PENDAhuluan}

Diabates Melitus (DM) adalah salah satu penyakit genetik yang cukup berbahaya.Pada dasarnya penyakit ini adalah salah satu penyakit kronis yang di sebabkan karena pangkreas mengalami masalah dalam memproduksi insulin di dalam tubuh,ataupun tubuh tidak mampu dalam menggunakan insulin dalam tubuh.Pada dasarnya penyakit ini biasanya terkena pada kalangan kanak-kanak dan dewasa muda karena disebabkan oleh faktor genetik ataupun pola makan yang tidak teratur. Perserikatan Bangsa Bangsa (PBB) membuat sebuah pernyataan yaitu berupa perkiraan dimana pada tepatnya tahun 2000 dimana penderita diabetes rata-rata berada diatas umur 20 tahun berkisar 150 juta orang dan dalam kurun waktu yang akan datang yaitu 25 tahun setelahnya tepatnya 2025 ,jumlah itu akan meningkat mencapai 300 juta orang atau 2 kali lipatnya [1].Adapun pada penilitian ini pembahasan berfokus pada Diabates Melitus tipe 1 dimana penyakit ini bisa di sebut juvenile-ovset. Pada orang yang biasanya mengidap penyakit diabetes tipe 1 terjadi hiperglikemia yang ditandai dengan poliuria, polidipsia, polifagia dan 
pandangan kabur. Kadar gula darah normal pada saat puasa pada umumnya di kisaran <126 mg/ dl, sedangkan pada saat tidak puasa di kisaran <200 mg/dl [1].

Diabetes Melitus (DM) adalah sebuah keadaan dimana secara produksi insulin yang berada di dalam tubuh tidak mencukupi untuk mengubah glukosa yang dihasilkan karbohidrat ke dalam bentuk glikogen. Glukosa tidak dapat digunakan secara langsung oleh tubuh. Diabetes tidak terkontrol dapat menyebabkan penurunan air liur (saliva), sehingga mulut terasa kering. Saliva mempunyai kemampuan self-cleansing, yang di mana hal tersebut berfungsi sebagai pembilas dari sisa makanan dan minuman yang berada di dalam mulut. Salah satu akibat dari ini adalah terjadinya Halitosis. Halitosis disebabkan oleh terbentuknya Volatile Sulfur Compond (VSC), yang terbentuk dari beberapa kumpulan gas yang mengandung sulfur yang dilepaskan saat mengehembuskan nafas. VSC terdiri dari hydrogen sulfide (H2S), methane thiol atau methyl mercaptan (CH3SH) dan dimethylsulfide (CH3SCH3) [2].

Cara pengecekan halitosis untuk menghitung kadar glukosa dalam tubuh dapat dilakukan dengan menghitung kadar dari Volatile Sulfur Compounds (VSCs) yang dihembuskan melalui mulut. Mengidentifikasi napas penderita diabetes mellitus dan non penderita diabetes melitus dapat dilakukan dengan menggunakan sejumlah sensor yaitu sensor gas TGS 2602 yang mampu mendeteksi unsur hydrogen sulfida dan MQ- 4 yang mampu mendeteksi unsur metana [2]. Hasil deteksi sensor adalah berupa data analog yang di konversikan dalam bentuk digital dan akan diolah berdasarkan metode filter lowpass, dimana pada riset ini akan dicari selisih pada kondisi humidity sensor guna mendapatkan hasil yang akurat..Hasil dari proses filtering tersebut diproses untuk mendapatkan pola data kadar VSCs dari nafas. Hasil pola data inilah yang akan dijadikan sebagai data input untuk K-Nearest Neighbour sebagai data untuk pengambilan keputusan dengan metode klasifikasi euclidien dan Reggresion [3]

\section{METODE PENELITIAN}

\section{Sinstem Sensor Nafas}

Penelitian ini merupakan lanjutan serta pengembangan dari penelitian sebelumnya, di mana penelitian ini berfokus pada pembuatan alat desain sistem pengecekan glukosa dalam darah untuk menemukan kinerja yang efektif dan terbaharukan dalam menangani penderita Diabetes Melitus (DM) atau Non Diabetes Melitus [1] [2] [4]. Makalah sebelumnya hanya membahas pendeteksian pasien menggunakan metode jaringan saraf tiruan yang dirancang untuk mengetahui apakah pasien hanya mempunyai penyakit Diabetes Melitus menggunakan metode nafas [5]. Namun, jurnal ini hanya mengimplementasikan nilai pada gas dan hanya menghasilakan pernyataan iya ataupun tidak dan tanpa teknik pembelajaran pada sistem deteksi glukosa serta tidak menampilkan dalam bentuk satuan mg/dl. Makalah lain membahas desain sistem deteksi glukosa dalam darah dengan metode pernafasan secara berkala dan untuk memantau kondisi pasien secara langsung tuntuk menemukan indikasi apakah pasien mengalami naik turunya gula dalam darah [6]. Perancangan sistem jurnal menggunakan metode Naive Bayes dalam menentukan skema regulasi pada sensor terkait dengan indikasi mempunyai penyakit diabetes melitus ataupun tidak.

Selain itu, ada referensi penelitian untuk jurnal " Rancang Bangun Alat Portable Deteksi Kadar Glukosa Dalam Darah Pada Gejala Diabetes Melitus Tipe 1 Berbasis ATMEGA 8535" yang ditulis oleh Ahmad San Wicaksono, ST Pada Tahun 2018 Jurnal Disnakertrans Pemprov DKI Jakarta, Hasil sistem pendeteksi dari riset yang telah di lakukan ini hanya mendeteksi Tegangan dalam bentuk Volt, serta maksimalisasi dengan $A=2,5$. Serta tidak menggunakan algoritma klasifikasi tertentu [4]. Oleh karena itu, penulis melakukan pengembangan penelitian dari jurnal yang disebutkan dengan menambahkan konsep IoT dan algoritma machine-learning dengan tujuan untuk menyediakan sistem yang lebih fleksibel dan dapat digunakan dengan mudah serta mendapatkan hasil yang berupa kadar dalam gula darah dalam satuan $\mathrm{mg} / \mathrm{dl}$ yang dimana dari hasil yang sebelumnya untuk tindakan pendeteksian glukosa dalam darah secara non-invasive tidak menghasilkanya. Selain itu, penulis mengganti metode klasifikasi Naïve Bayes dengan metode klasifikasi K-Nearest Neighbour Reggresion yang dimaksudkan untuk dapat melakukan pencarian tingkat prediksi terhadap kadar glukosa yang berada pada darah tersebut. Metode klasifikasi KNearest Neighbour digunakan dengan memanfaatkan data yang berasal dari sensor aktif. Data tersebut dapat digunakan sebagai referensi untuk pengolahan data dalam menggunakan metode klasifikasi KNearest Neighbour dalam menentukan ukuran tingkat prediksi terhadap kadar glukosa dalam darah. Sistem sensor nafas menggunakan mikrokontroler dan sensor pendeteksi seperti, sensor gas.Metode KNearest Neighbour adalah metode yang menggunakan algoritma supervised untuk selanjutnya yang dimana hasil dari query instance baru akan diklasifikan berdasarkan jumlah terbanyak dari kategori pada 
K-NN [3]. Tujuan dari proses ini adalah mengkelompokan objek baru menuru atribut dan training samplenya. Classifier pada halnya tidak menggunakan model apapun untuk dicocokkan dan di dasari pada memori. Diberikan sebuah titik query, yang dimana akan dipakai sejumlah k objek atau (titik training) yang mendekati dengan titik query. Klasifikasi menggunakan pemungutan suara terbanyak diantara klasifikasi dari ke obyek. algoritma K-NN menggunakan metode standar klasifikasi ketetanggaan yang dimana hal itu adalah nilai prediksi dari query instance yang baru.algoritma ini sedikit dimodifikasi dengan tambahan regression agar mendapatkan sebuah nilai berupa angka.

Kami mengusulkan sistem sensor nafas untuk meningkatkan dan memperbaruhi kinerja sistem sebelumnya. Pembaruan desain sistem berupa aspek ekonomi serta kemudahan menggunakan alat yang menggunakan hasil tingkat prediksi kadar glukosa dalam darah dan sumber gas dari dalam tubuh. Gambar 1. Menunjukkan deskripsi sistem sensor nafas. Sistem sensor nafas memiliki fungsi untuk dapat mendeteksi kadar glukosa dalam darah dari sesorang melalui mulut yang dikeluarkan dalam bentuk nafas. Pada perangkat sistem terdapat dua sensor gas. Sensor berfungsi untuk mendeteksi kadar hidrogen sulfida $(\mathrm{H} 2 \mathrm{~S})$ dan metana $(\mathrm{CH} 4)$ dengan seseorang yang utamanya memiliki penyakit gula darah ataupun normal, terutama pengidap diabetes melitus. Pengidap penyakit diabetes melitus dipastikan bahwa pada mulut orang tersebut mengalami penurunan saliva (air liur), sehingga mulut terasa kering yang mempengaruhi bau mulut dan kemampuan pembersihan mulut atau self-cleansing di dalam mulut, karenanya menjadi alasan pemilihan sensor [2]. Fungsi Sensor adalah untuk memberikan nilai input sesuai dengan unit fungsionalitas pada sensor.Nilai input diatur oleh Arduino Uno yang dapat mengirimkan pada platform Arduino IDE. Selanjutnya akan di masukkan data secara manual pada platform Google cloud untuk diproses menggunakan metode K-Nearest Neighbour. Setelah melalui pemrosesan data, nilai output akan keluar dalam satuan glukosa dalam darah yaitu $\mathrm{mg} / \mathrm{dl}$.

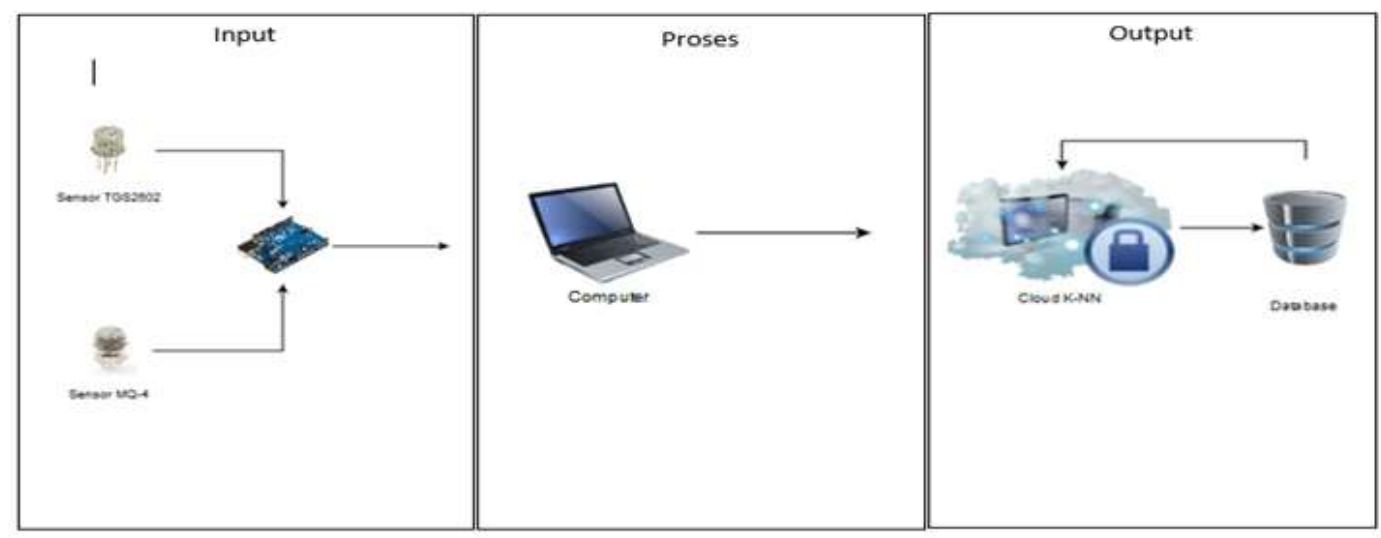

Gambar 1 Alur Rancangan Sistem Sensor Nafas

Sistem semsor nafas ini hanya memiliki satu fungsi yaitu: Perangkat sistem mampu mendeteksi kadar Hidrogen Sulfida (H2S) dan Metana (CH4) dalam bentuk gas, perangkat sistem dapat diintegrasikan dengan platform Arduino Uno.Hasil data yang telah didapatkan dan dimodelkan menggunakan bahasa python3 serta diintengraskan dengan Algoritmita server Cloud selanjutnya akan dikeluarkan nilai menggunakan platform web pythonanywhere dan dapat dimonitor langsung melalui web interface berapa hasil perhitungan kadar $\mathrm{mg} / \mathrm{dl}$ darah tersebut ataupun serial plotter dengan menggunakan metode klasifikasi K-Nearest Neighbour, pengguna dapat memonitor data dari platform Arduino IDE yang memiliki tingkat perkiraan terhadap berapa orang yang mengidap penyakit gula darah dan Arduino berfungsi sebagai jalur input dan perangkat terpisah terhadap output data pada server bersama dengan perangkat sistem. Dalam sistem sensor nafas, ada diagram alir sistem yang menunjukkan bagaimana alat sistem bekerja dengan serangkaian proses secara bertahap. Gambar 2. Menunjukkan alur diagram sistem. 


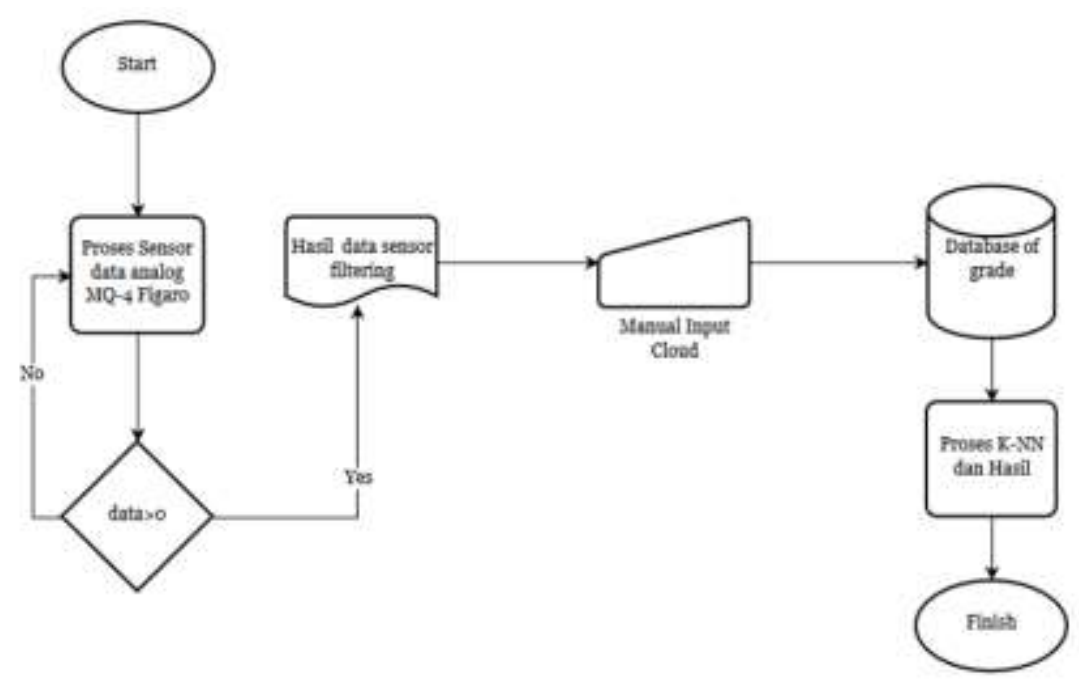

Gambar 2 Flowchart Alur Diagram Sistem Sensor Nafas

Dalam tulisan ini, ada banyak penggunaan Hardware dan spesifikasinya yang digunakan dalam implementasi sistem. Tabel 1 menunjukkan spesifikasi sistem Hardware. Selain Hardware yang digunakan, Software untuk mendukung penelitian adalah sebagai spesifikasi di bawah ini: Sistem Operasi Windows 10, Alat: Arduino IDE, plot.ly, algorihtmia cloud, pythonanywhere.

Tabel 1 Spesifikasi Sistem Hardware

\begin{tabular}{ccc}
\hline Hardware & Tipe Hardware & Fungsi Hardware \\
\hline & & Perangkat mengatur data input yang sambungkan \\
Mikrokontroller & Arduino Uno & dengan sensor \\
Sensor Gas & MQ-4 dan Figaro TGS2602 & Sensor deteksi gas Metana dan HidrogenSulfida \\
Glukometer & Safeaccu & Untuk pengambilan dataset dan pembanding alat \\
\hline
\end{tabular}

\section{Data dan Testing Skenario}

Data penelitian diambil menggunakan glukometer dan beberapa sensor gas, MQ-4 dan FigaroTGS2602. Data yang dikumpulkan adalah kadar dari dua jenis gas dan satu tetes gula darah, yaitu HidrogenSulfida(H2S), Metana(CH4), satu tetes gula dalam mg/dl. Setiap orang diambil 3 kali di mana semua data berjumlah 45 data. Pada 45 data dibagi menjadi 40 data untuk pelatihan dan 5 data untuk pengujian. Data tersebut digunakan untuk menerapkan proses klasifikasi K-Nearest Neighbour ]ke perangkat sistem dalam menemukan keakuratan kadar glukosa yang dihitung. Proses pengujian klasifikasi K-Nearest Neighbour menggunakan alat algorithmia cloud dan pythonanywhere yang terintegrasi serta dibandngkan dengan penelitian akurasi penelitian sebelumnya. Pengumpulan data pelatihan dan pengujian diberikan dalam bentuk beberapa grafik sebar dalam bentuk tiga dimensi pada Gambar 3 .

Dalam tulisan ini berbagai fungsi mikrokontroler, sensor dan glukometer pada perangkat sistem sensor gula darah akan diuji. Hal ini dilakukan dengan melihat kinerja sesuai dengan kebutuhan sistem. Selain pengujian alat sistem, penelitian menguji penerapan proses klasifikasi K-Nearest Neighbour ke sistem dengan menggunakan integrasi server berbasis cloud algorihmia dan pythonanywhere dalam pengambilan dan pemrosesan data. Oleh karena itu, penelitian ini melakukan pengujian dengan skenario bertahap, yaitu sebagai berikut:

\section{Uji perangkat sistem sensor nafas.}

Sistem ini menggunakan sensor gas MQ-4 dan Figaro-TGS2602. Sensor diuji terhadap Lima jenis unsur senyawa yaitu Metana (CH4), Air(H2O), KarbonDioksida (CO2), HidrogenSulfida (H2S), Alkohol $(\mathrm{CH} 3 \mathrm{OH})$ yaitu kondisi bebas asap (normal), dan teperature normal 27-33 derajat celcius. Alasan penggunaan lima jenis unsur senyawa tersebut adalah untuk mencoba nilai konten asap dalam pengujian terhadap sensor gas. Mikrokontroler Arduino Uno terintegrasi ke dalam platform Arduino IDE [1] bersama dengan perangkat sensor. Konfigurasi yang diterapkan pada cloud server akan dilakukan dengan

Pendeteksian Kadar Glukosa dalam Darah pada Gejala Diabetes Tipe 1 Menggunakan Algoritma KNearest Neighbor dengan Metode Nafas (Muhammad Shibgah Aulia) 
mengatur nilai input yang sudah dimodelkan dan akan dilkeluarkan dalam bentuk mg/dl pada web interface.

Dara-set Glix:ose

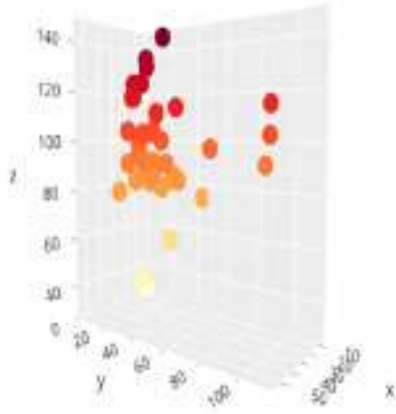

Data-set Glucose

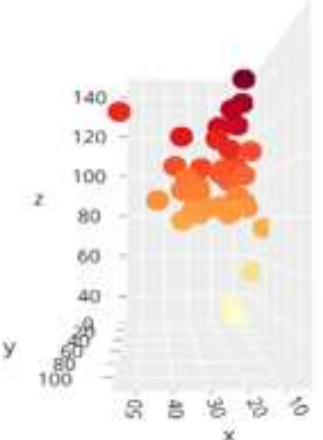

Datz-set Glucose

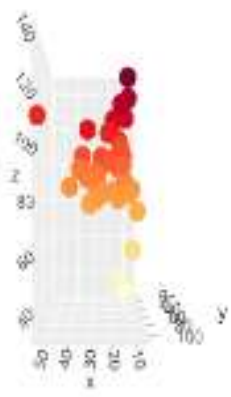

Gambar 3 Plot.ly Chart untuk 40 data set pada pendeteksian gula darah X=Metana (ppm), Y=HidrogenSulfida (ppm), Z=Glukosa (mg/dl).

\section{Tes proses klasifikasi K-Nearest Neighbour.}

Sistem mengumpulkan data sampel pada perangkat sistem dari deteksi sensor dalam bentuk data numerik sebanyak 45 data dari lima tipe senyawa berbeda. Penelitian kemudian membagi data di mana 40 dari data adalah untuk data pelatihan dan 5 data lainnya untuk data pengujian. Data diuji dengan aplikasi klasifikasi K-Nearest Neighbour yang disediakan oleh alat algorithmia dan pythonanywhere. Proses klasifikasi K-Nearest Neighbour bertujuan untuk menemukan perkiraan nilai kadar glukosa dalam darah. Pada pengjuian ini peneliti menggunakan metode perhitungan euclidean distance dengan $\mathrm{k}=5 \mathrm{dan}$ di gabungkan dengan sedikit regression. Pada dasarnya mengapa menggunakan $\mathrm{k}=5$ dikarenakan berdasarkan pada algoritmia untuk k=5 adalah k yang paling akurat.Berikut rumus dan penjelasanya:

$$
\text { istance }(x, y)=\sqrt{\sum_{k=1}^{n}\left(x_{i k}-y_{j k}\right)^{2}}
$$

Distance : adalah jarak serta hasil yang di gunakan untuk prediksi.

$\mathrm{X} \quad$ : adalah hasil data yang didapatkan pada deteksi Metana.

Y : adalah hasil data yang didapatkan pada deteksi H2S.

\section{Uji Kinerja Keseluruhan.}

Pada tahap ini penelitian menguji fungsionalitas pada kondisi perangkat alat yang dapat berfungsi dari tingkat pengiriman dan penerimaan data input dari Arduino IDE dan menghasilkan data dalam bentuk hasil prediksi yang diproses dengan pythonanywhre yang dapat menentukan nilai glukosa dalam darah yang telah disesuaikan dengan prediksi hasil. Metrik yang diuji adalah akurasi dan penundaan. Akurasi diuji dengan membandingkan hasil nyata dengan hasil teoretis dan membandingkan dengan alat uji dari penelitian sebelumnya.

\section{HASIL DAN PEMBAHASAN}

\section{Hasil Uji Sensor pada Sensor Nafas}

Uji yang dilakukan adalah uji senyawa dalam pengujian sensor, para peneliti mengamati kinerja fungsi sensor yang dapat diintegrasikan dengan menggunakan perangkat lunak Arduino IDE. Sensor yang terkandung dalam sistem alarm kebakaran terdiri dari sensor gas, MQ-4 dan Figaro TGS2602. Pengamatan atas hasil tes ini dalam kinerja yang sukses dengan memiliki hasil sensor yang terkandung dalam Gambar 4. 

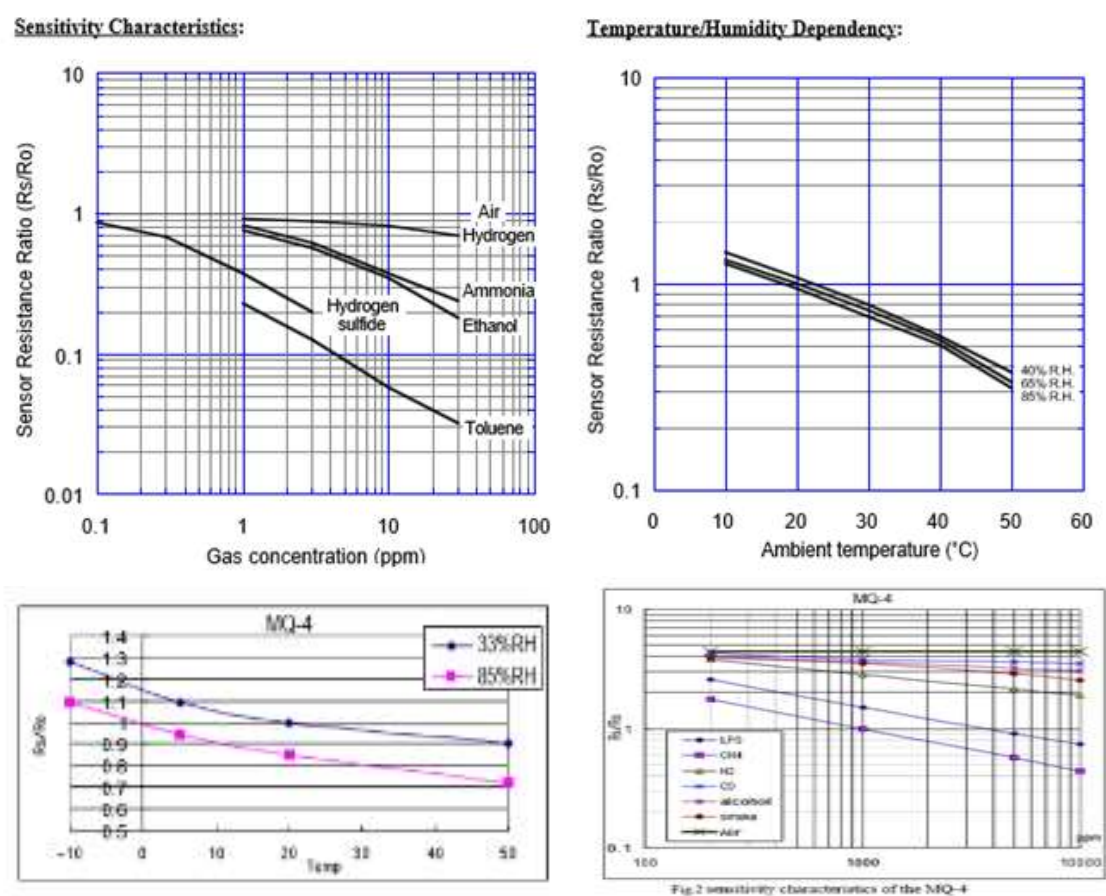

Gambar 4 Hasil uji sensor MQ-4 [7] dan Figaro TGS2602 [8]

\section{K-Nearest Neighbour pada Hasil Uji Data}

Hasil tes diperoleh pada penerapan proses klasifikasi K-Nearest Neighbour serta Cloud menggunakan pythonanywhere yang dapat di akses melalui laman http://dazalls.pythonanywhere.com/gluko/\{Kadar Metana $\} /\{$ Kadar HidrogenSulfida $\}$ dari 40 data pelatihan memiliki hasil rata-rata dan nilai standar deviasi yang digunakan untuk proses klasifikasi. Rata-rata dan standar deviasi 40 data pelatihan dapat ditunjukkan pada Tabel 2. Hasil rata-rata dan standar deviasi digunakan untuk proses klasifikasi pada 5 pengujian data yang kemudian setelah selesainya proses hasil klasifikasi muncul dalam bentuk ambang nilai kadar glukosa dan tingkat akurasi. Hasil dari klasifikasi dapat terlihat pada Tabel 3.

Tabel 2 Hasil Rata-Rata serta contoh sample data yang di uji beserta rata-rata, dan standar deviasi

\begin{tabular}{lrlrrrr}
\hline \multicolumn{7}{c}{ data test } \\
\multicolumn{1}{c}{ nama } & umur & sex & mq4 & tgs & glucose level \\
\hline Bagas & 20 & m & 28 & 9 & 90 \\
\hline Ihsan & 21 & M & 9 & 2 & 126 \\
\hline Amran & 23 & M & 25 & 6 & 104 \\
\hline Vithroh & 20 & M & 29 & 19 & 96 \\
\hline Adli & 19 & M & 44 & 41 & 87 \\
\hline
\end{tabular}

$$
\text { Accuration dat } \alpha=\frac{\text { Sum correct data testing classifiar }}{\text { Sum data testing }} \times 100 \%
$$

Tabel 3 Hasil data testing beserta dengan akurasi yang di dapatkan

\begin{tabular}{lcrr}
\hline \multicolumn{1}{c}{ jenis } & deviasi & rata-rata & Presisi data \\
\hline gula darah & 23,56681718 & 95.3 & $25 \%$ \\
\hline Mq-4 & 11,87488192 & 19.75 & $58 \%$ \\
\hline $\operatorname{tgs} 2602$ & 25,86640976 & 24,825 & $100 \%$ \\
\hline
\end{tabular}

Pendeteksian Kadar Glukosa dalam Darah pada Gejala Diabetes Tipe 1 Menggunakan Algoritma KNearest Neighbor dengan Metode Nafas (Muhammad Shibgah Aulia) 


\begin{tabular}{|c|c|c|c|c|c|c|}
\hline \multicolumn{7}{|c|}{ data train } \\
\hline nama & umur & $\operatorname{sex}$ & $\mathrm{mq4}$ & $\operatorname{tgs}$ & glucose level & akurasi \\
\hline Bagas & 20 & $\mathrm{~m}$ & 28 & 9 & 90 & $100 \%$ \\
\hline Ihsan & 21 & $\mathrm{M}$ & 9 & 2 & 95 & $75 \%$ \\
\hline Amran & 23 & $\mathrm{M}$ & 25 & 6 & 104 & $100 \%$ \\
\hline Vithroh & 20 & M & 29 & 19 & 96 & $100 \%$ \\
\hline \multirow[t]{3}{*}{ Adli } & 19 & M & 44 & 41 & 87 & $100 \%$ \\
\hline & & & Nilai $\mathrm{k}$ & & & \\
\hline & & & $\mathrm{k}=5$ & & & \\
\hline
\end{tabular}

Berdasarkan hasil klasifikasi dari 5 data pengujian, setiap hasil dari nafas tersebut memiliki 1 data yang menunjukkan kondisi normal dapat memprediksi 4 data dengan benar dan 1 data normal telah diprediksi salah. Untuk prediksi pengidap diabetes rokok 2 benar tetapi ada 3 yang diperkirakan salah Kondisi dari orang normal dan pengidap diabters dapat memprediksi data dengan cukup benar akan tetapi belum terlalu akurat sehingga hasil tingkat akurasi yang diperoleh pada 5 data pengujian sebesar $80 \%$. Namun, hasil tes menunjukkan bahwa pada glukosa memiliki presisi kelas yang rendah sehingga berdampak pada tingkat kinerja akurasi prediksi pada sistem sensor nafas tersebut.

\section{Hasil Uji K-Nearest Neighbour pada Pythonanywhere untuk Sistem Sensor Nafas}

Pengujian klasifikasi K-Nearest Neighbour di Pythonanywhere dilakukan dengan mengamati hasil dari masing kadar metana dan hidrogen sulfida untuk melihat keberhasilan prediksi dalam setiap data Berikut ini data hasil pengujian pada Tabel 4. Ini menunjukkan 10 data hasil tes eksperimen yang diperoleh dari orang normal dan pengidap dimana 6 data sesuai dengan kondisi status yang benar dan untuk 4 data memiliki prediksi yang salah sehingga akurasi hasil yang diperoleh dari semua data diuji untuk $66 \%$. Prediksi pengujian pengamatan setiap nafas dilakukan dengan kondisi suhu udara normal.

Tabel 4 Hasil testing data dengan pythonanywhere

\begin{tabular}{cccc}
\hline Tipe Pasien & Testing & Sukses & Gagal \\
\hline Normal & 5 & 4 & 1 \\
Diabetes tipe 1 & 5 & 2 & 3 \\
Total & 10 & 6 & 4 \\
\hline
\end{tabular}

Berdasarkan hasil pengujian dengan tingkat akurasi prediksi $40 \%$ total data pengujian dibetes tipe 1 karena adanya indikasi unsur senyawa Metana dan HidrogenSulfida yang tidak sesuai dan tidak terfilter dengan baik pada penggunaan sensor MQ-4 dan FigaroTGS2602 sehingga mempengaruhi kinerja sistem.

\section{KESIMPULAN}

Berdasarkan pengujian beberapa, hasil menunjukkan bahwa penerapan metode klasifikasi K-Nearest Neighbour pada sistem sensor nafas dapat meningkatkan kisaran tingkat akurasi dari 66\% menjadi $80 \%$. Perangkat sistem telah bekerja dengan cukup baik dalam pendeteksian hanya saja belum memenuhi standar akurasi yang dibutuhkan dalam dunia medik khususnya bagi pasien yang mengi ]dap penyakit diabetes melitus.

\section{UCAPAN TERIMA KASIH}

Terima kasih kepada Allah subwanahuwataala serta orang tua ,kerabat ,para pembimbing yaitu pak Maman Abdurrahman dan pak Aji Gautama Putrada dalam membibing serta memberi masukan terhadap jurnal serta tugas akhir ini.Tidak lupa pula dengan dosen Wali saya bu Veronikha Effendy serta dosendosen yang saya tidak bisa sebutkan satu persatu namanya.

\section{REFERENSI}

[1] D. Arnike, "Efikasi Diri Pasien Diabetes Melitus Tipe 2 di RSUP. H. ADAM MALIK MEDAN," Skripsi , pp. 1-20, 2017.

[2] W. A. S, "Rancang Bangun Alat Portabel Deteksi Kadar Glukosa Dalam Darah Pada Gejala Diabetes Melitus Tipe 1 Berbasis ATMEGA 8535," Jurnal Disnakertas Pemprov DKI Jakarta, pp. 1-5, 2018. 
[3] Yafis Sukma Kurniawan, Dr.Ir. Bambang Hidayat, DEA., Suci Aulia, ST., MT, "Deteksi Dan Klasifikasi Tingkat Keparahan Retinopati Diabetes Dengan Menggunakan Metode Klasifikasi K - Nearest Neighbor," e-Proceeding of Engineering , pp. 468475, 2017.

[4] Mohammad Hafiz Hersyah, Andrizal , Revinessia, "IDENTIFIKASI PENYAKIT DIABETES MELLIUS MELALUI NAFAS BERBASIS SENSOR GAS DENGAN METODE FAST FOURIER TRANSFORM DAN BACKPROPAGATION," Journal of Information Technology and Computer Engineering, vol. II, no. 2, pp. 35-41, 2018.

[5] Anand Thati1, Arunangshu Biswas, Shubhajit Roy Chowdhury and Tapan Kumar Sau, "BREATH ACETONE-BASED NONINVASIVE DETECTION OF BLOOD GLUCOSE LEVELS," International Journal on Smart Sensing and Intelligent System, vol. 8, pp. 1244-1260, 2015.

[6] D.Kaleeswari ;S.Nandhini;M.Sajna ;R.Usha ;M.Premkumar, "Detection of blood glucose level For type 1 diabetic patient by Using non-invasive breath measurement," D.Kaleeswari al. International Journal of Recent Research Aspects, pp. 273-276, 2017.

[7] D.Kaleeswari, S.Nandhini, M.Sajna, R.Usha, M.Premkumar, "Detection of blood glucose level For type 1 diabetic patient by Using non-invasive breath measurement," D.Kaleeswari al. International Journal of Recent Research Aspects ISSN: 23497688,, vol. IV, no. 4, pp. 273-276, 2017.

[8] F. U. inc, Writer, Figaro. [Performance]. Figaro USA inc, 2009.

[9] H. Electronics, Writer, Tecnichal data sensor MQ-4. [Performance]. Hanwei Electronics, 1986.

Pendeteksian Kadar Glukosa dalam Darah pada Gejala Diabetes Tipe 1 Menggunakan Algoritma KNearest Neighbor dengan Metode Nafas (Muhammad Shibgah Aulia) 